\title{
PERFORMANCE EVALUATION OF Fe (III) ADSORPTION ONTO BREWERS' SPENT GRAIN
}

\author{
0. C. Izinyon ${ }^{1}$, O. E. Nwosu ${ }^{2}$, L.0. Akhigbe ${ }^{3,}{ }^{*}$ and I. R. Ilaboya ${ }^{4}$ \\ 1,2,3,4 Department of Civil Engineering, University of Benin, Benin City. Edo State. NigERIA. \\ E-mail addresses: ${ }^{1}$ izinyon2006@yahoo.com, ${ }^{2}$ jeppcon@yahoo.com, ${ }^{3}$ loakhigbe@gmail.com, \\ 4id_rudolph@yahoo.com
}

\begin{abstract}
This work investigated the performance of locally available brewer's spent grain (BSG) as an adsorbent for the removal of Fe (III) from aqueous solution. The brewer's spent grain (BSG) was collected, processed and characterized using scanning electron microscope (SEM) and X-ray fluorescence (XRF) to assess its potential for the removal of Fe (III). Thereafter, batch adsorption technique was employed to evaluate the effects of adsorption variables such as pH, initial metal ion concentration, adsorbent dosage and contact time on the sorption efficiency of BSG. The maximum adsorption time was fixed at 120minutes with a stirring speed of 100rpm. Experimental data obtained were then analyzed using selected isotherms and kinetic models such as Langmuir isotherm, Freundlich isotherm, Pseudo-First order and Pseudo-Second order kinetic models. SEM result revealed the presence of microporous structure within the surface of BSG thus making it a good candidate for metal ion removal. Based on the linear coefficient of determination $\left(\mathrm{r}^{2}\right)$, it was observed that the experimental data fitted well with the Langmuir isotherm model $\left(\mathrm{r}^{2}=0.9940\right.$ for raw BSG and 0.9946 for the treated BSG). In addition, the reaction mechanism that accompanies the adsorption of Fe (III) unto BSG was best described by the pseudo-second order kinetic model ( $\mathrm{r}^{2}$ $=0.9823$ for raw BSG and 0.981 for the treated BSG). Finally, maximum adsorption efficiencies of 66\% and $77 \%$ were obtained for both the raw and treated BSG for optimum adsorption time of 120 minutes, $p H 8.0$ and adsorbent dose of $1.0 \mathrm{~g} / 50 \mathrm{ml}$ solution.
\end{abstract}

Keywords: Brewers'spent grain; Adsorption; Fe (III); Isotherm; Kinetics.

\section{INTRODUCTION}

The quality of our environment is deteriorating with the largest cities reaching saturation points and unable to cope with increasing pressure on their infrastructure. Water pollution due to toxic heavy metals from natural and anthropogenic sources has been a major cause of concern for environmental engineers. Most of these heavy metals discharged into water bodies are deleterious to human health and the environment [1]. The release of large quantities of hazardous materials into the natural environment has resulted in a number of environmental problems owing to their non-biodegradability and persistence of these metals in the ecosystem. Furthermore, these heavy metals accumulate and enter the human systems through the food chain and thus pose a significant danger to human health [2, 3].

Toxic heavy metals normally enter into the water bodies through uncontrolled disposal of waste water, metal plating, mining activities, smelting, battery manufacture, tanneries, petroleum refining, paint manufacture, pesticides, pigment manufacture, printing and photographic industries, etc. Several episodes due to heavy metal contamination in aquatic environment increased the awareness about the heavy metal toxicity. These include the Minamata tragedies due to mercury poisoning and "Itai-Itai" diseases in Japan due to cadmium toxicity, which are well known [4].

Numerous treatments and abatement techniques have been employed to remediate heavy metals in wastewater. They include precipitation, electrofloatation, ion exchange, reverse osmosis, solvent extraction, electro dialysis, membrane separation and adsorption. Some of these methods have been found to be limited due to high capital and operational costs. High operational costs may be associated with the generation of secondary waste, which presents 
additional treatment problems, such as the large quantity of sludge generated by precipitation processes. Ion exchange, reverse osmosis and adsorption are more attractive processes because the metals' values can be recovered along with their removal from the effluents [5]. However reverse osmosis and ion exchange may not be economically feasible in certain scenarios due to their relatively high investment and operational cost. Adsorption in comparison with other methods is attractive in terms of its efficiency and ease with which it can be applied especially in the removal of heavy metals from wastewater [5].

Adsorption is one of the easiest, safest and most costeffective methods for the removal of these metals from industrial effluents. It is suitable even when the metal ions are present in concentration as low as $1 \mathrm{mg} / \mathrm{l}$. The major advantage of an adsorption system for water pollution control is less investment in terms of both initial cost and operational cost, simple design, easy operation and no effect of toxic substances compared to conventional biological treatment processes [6].

Activated carbon is a highly effective adsorbent for the removal of heavy metal-ion from the concentrated and dilute metal bearing effluents but the process is not popularly used by small and medium scale industries for the treatment of their metal bearing effluents, because of its high manufacturing cost. For this reason, the use of low cost materials as adsorbent for metal ion removal from wastewater has been highlighted. However, efforts towards the development of new adsorbent and improving the existing ones are receiving attention. Plant wastes, agricultural and industrial by-products have been utilized as cheap and unconventional adsorbents for heavy metals removal from aqueous solutions $[6,7]$. Spent grains, are primarily mixture of grain and grain husks, with the majority of its sugars extracted. They are composed of cellulose, hemicellulose and lignin and are the by-products of mashing process in brewery. The amount of spent grain generated could be about $85 \%$ of the total by-products [9]. Spent grain has many applications because of its high protein and fibre content. Spent grain applications range from production of bio-plastics and bio-fuel, to agricultural uses as animal feed and compost material, to reuse as food for people [8].

One of the promising by-products that have drawn the attention of researchers is brewer's spent grain (BSG) [9]. It has been found to be a potentially valuable resource for industrial exploitation due to its high availability and low cost. The variation in percentage composition of the components was attributable to the variety of the grains used; harvest time, malting and mashing conditions and the quality and type of adjuncts used during the process. BSG has a significant potential as an adsorbent for application in the remediation of metal contaminated wastewater streams $[6,9]$. In a study investigating the use of BSG for the removal of $\mathrm{Cu}$ (II) ions from aqueous solutions, a maximum adsorption capacity of $10.47 \mathrm{mg} / \mathrm{g}$ dry weight at $\mathrm{pH} 4.2$ was achieved [9].

The aim of this study was to investigate the performance of BSG for the removal of Fe (III) from aqueous solutions in batch systems while studying the influence of certain parameters: $\mathrm{pH}$, initial metal ion concentration, contact time and adsorbent dose on the metal removal process. Furthermore the experimental data were analyzed using adsorption isotherms and kinetic models.

\section{MATERIALS AND METHODS}

\subsection{Equipment/Materials/Chemicals}

Equipment, materials and chemicals used for this research work are presented as shown in Tables 1, 2 and 3 respectively.

\subsection{Collection/Preparation of Adsorbent Form BSG}

Brewers' spent grain (BSG) was obtained from Intafact Breweries Limited, Onitsha, Anambra State, Nigeria. The adsorbent was air dried, pulverized and sieved using 180-micrometer mesh size sieve. The sieved sample was thoroughly washed with distilled water to remove brewers' residues and oven dried at $100^{\circ} \mathrm{C}$ for 1 hour.

Table 1: Equipment used

\begin{tabular}{lccc}
\hline \multicolumn{1}{c}{ Equipment Name } & Model & Manufacturer & Year \\
\hline Atomic Absorption Spectrophotometer (AAS) & SOLAR 969 & UNICAM UK & 2010 \\
X-Ray Fluorescence (XRF) & APEX 3022 & England & 2010 \\
Digital Weighing Balance & Kern 001 & England & 2000 \\
Hot Plate with Magnetic Stirrer & HJ-3D & England & 2010 \\
Oven & DHG 9101-2A & Searchtech UK & 2010 \\
Scanning Electron Microscope (SEM) & APEX 3020 & England & 2010 \\
\hline
\end{tabular}


Table 2: Reagents purchased at Stanvac Chemicals Benin

\begin{tabular}{llc}
\multicolumn{3}{c}{ City } \\
\hline \multicolumn{1}{c}{ Reagents Name } & \multicolumn{1}{c}{ Grade } & Minimum Assay \\
\hline Iron (III) Chloride & Analytical grade & $98 \% \mathrm{v} / \mathrm{v}$ \\
Distilled Water & $100 \%$ distilled & $100 \%$ distilled \\
Nitric Acid & Analytical grade & $69.5 \% \mathrm{v} / \mathrm{v}$ \\
Sodium Hydroxide & Analytical grade & $32 \% \mathrm{w} / \mathrm{w}$ \\
Hydrochloric Acid & Analytical grade & $50 \% \mathrm{v} / \mathrm{v}$ \\
Sodium Thiosulphate & Analytical grade & $98 \% \mathrm{w} / \mathrm{w}$ \\
lodine Solution & Analytical grade & $99.5 \% \mathrm{w} / \mathrm{w}$ \\
Methylene Blue & Analytical grade & $99 \% \mathrm{w} / \mathrm{w}$ \\
\hline
\end{tabular}

Table 3: Materials used

\begin{tabular}{ll}
\hline \multicolumn{1}{c}{ Name } & \multicolumn{1}{c}{ Description } \\
\hline Brewery Spent Grain (BSG) & Brewers by product \\
Whatman Filter Paper & 150mm diameter \\
Beakers & Pyrex product \\
Funnels & Pyrex product \\
Reagent Bottles & Pyrex product \\
Sample Bottles & Marcaty Bottles \\
\hline
\end{tabular}

The adsorbent was soaked in $500 \mathrm{~mL}$ of $0.3 \mathrm{M} \mathrm{HNO}_{3}$ solution to remove any soluble biomolecules that might interact with the metal ions during the adsorption process and to open up the microspores of the adsorbent in readiness for the adsorption process. This adsorbent was termed 'raw BSG'. A portion of the raw BSG was treated with $0.5 \mathrm{M} \mathrm{NaOH}$ solution for 4 hours at room temperature [10] and then washed with distilled water to remove excess $\mathrm{NaOH}$ until constant supernatant $\mathrm{pH}$ was reached. Thereafter, it was oven dried at $70^{\circ} \mathrm{C}$ for 2 hours. The BSG treated with $\mathrm{NaOH}$ was termed 'treated BSG'.

\subsection{Characterization of Raw BSG}

\subsection{1: Physical Characterization}

To assess the physical properties of the raw BSG, the following tests were conducted:

Analysis of microstructure: The microstructures, composition and morphology of the brewer's spent grain were analyzed using scanning electron microscopy (APEX 3020 PSEM 2) to give adequate information about its morphology and topological presentations.

Moisture content determination: Thermal drying method was used in the determination of moisture content of the BSG. 1.0g of the dried sample was weighed and placed in washed dried and weighed crucible. The crucible was then placed in an oven and dried at $105^{\circ} \mathrm{C}$ to constant weight for 1 hour. The percentage moisture content (\%MC) was computed as follows [28].

Moisture content (\%)

$$
=\frac{\text { Loss in weight on drying }}{\text { Initiaal weight on drying }} \times 100
$$

Surface area, microspore volume and total pore volume Estimation: The surface area, microspore volume and total pore volume of BSG were estimated using the iodine and methylene blue number. The iodine and methylene blue numbers were determined using standard methods as described by ASTM D4607-94 [21, 29]. Data obtained were then analyzed using standard software (SCAC structural characterization of Activated carbon) to compute the surface area, microspore and total pore volume respectively [24].

Apparent density determination: Mass per unit volume relationship was employed to determine the apparent density of the adsorbent.

\subsubsection{Chemical Characterization}

To evaluate the chemical properties of the BSG, the following tests were conducted

Surface $p H$ determination: Suspension $(10 \% \mathrm{w} / \mathrm{v})$ of the adsorbent was prepared and allowed to stand for 0.5 hours under constant stirring speed of $100 \mathrm{rpm}$ using a magnetic stirrer. The electrode of the $\mathrm{pH}$ meter was then dipped into the solution after stirring in other to determine its $\mathrm{pH}$ value [27].

Analysis of the chemical composition: The chemical composition of the adsorbents was studied using XRay Fluorescence (XRF) APEX 3022. Chemical digestion of the solid adsorbent was done as follows: (1:1) mixture of $0.025 \mathrm{M}$ solution of hydrochloric acid and Nitric acid was prepared. A mixture of (1:10) of the solid adsorbent to acid solution was obtained and stirred for 30 minutes. The solution was filtered and the filtrate was used for the analysis.

For the determination of the ash content, methylene blue number and iodine number, standard experimental methods as described by Salwa et al. and ASTM D4607-94 were employed [21,29].

\subsection{Preparation of Aqueous Solutions}

The metal stock solution was prepared by dissolving iron (III) chloride $\left(\mathrm{FeCl}_{3} .6 \mathrm{H}_{2} \mathrm{O}\right)$ of analytical grade in distilled water. The stock solution was diluted with distilled water to give concentrations ranging from 5 to $30 \mathrm{mg} / \mathrm{l}$. 


\subsection{Adsorption Experiments}

Adsorption studies were carried out as follows:

1. To study the effect of $\mathrm{pH}$ on $\mathrm{Fe}^{3+}$ uptake, $1 \mathrm{~g}$ of BSG was contacted with $50 \mathrm{ml}$ aqueous solution of Iron (III) chloride at varying $\mathrm{pH}$ of 2, 4, 6, 8 and 10. pH adjustment was achieved by drop wise addition of $0.25 \mathrm{M}$ solution of $\mathrm{HCl}$ and $\mathrm{NaOH}$.

2. To study the effect of adsorbent dose on $\mathrm{Fe}^{3+}$ uptake, varying weight of the BSG ranging from $20,40,60,80,100$ and $120 \mathrm{mg}$ were contacted with $50 \mathrm{ml}$ aqueous solution of Iron (III) chloride at optimum $\mathrm{pH}$.

3. The effect of contact time on $\mathrm{Fe}^{3+}$ uptake was investigated by contacting $1 \mathrm{~g}$ of the BSG with $50 \mathrm{ml}$ aqueous solution of Iron (III) chloride. The solution was thereafter stirred and filtered at varying contact time of $20,40,60,80,100$ and 120 minutes respectively.

4. For the effect of initial metal ion concentration on the uptake of $\mathrm{Fe}^{3+}, 1 \mathrm{~g}$ of the BSG was contacted with $50 \mathrm{ml}$ aqueous solution of Iron (III) chloride at varying concentration of 5, 10, 15, 20 and $25 \mathrm{mg} / \mathrm{l}$.

For the various stages of experimentation, stirring of the solution was done using digital magnetic stirrer at constant stirring speed of $100 \mathrm{rpm}$. The solution was filtered using what man No 1 filter paper and the residual metal ion concentration was determined using atomic absorption spectrophotometer (AAS). The amount of heavy metal ions removed during the series of batch investigation was determined using the mass balance equation as [12]:

$$
q=\frac{v}{m}\left[C_{0}-C_{e}\right]
$$

In (2), q, defines the metal uptake $[\mathrm{mg} / \mathrm{g}] ; \mathrm{C}_{0}$ and $\mathrm{C}_{\mathrm{e}}$ : are the initial and equilibrium metal ion concentrations $[\mathrm{mg} / \mathrm{l}]$ respectively; $\mathrm{V}$ : is the volume of solution (ml) and $\mathrm{M}$ : is the mass of adsorbent used [g]. The efficiency of metal ion removal (\%) was calculated using [13].

$$
\text { Removal Efficiency (\%) }=\left(\frac{C_{0}-C_{e}}{C_{0}} \times 100\right)
$$

In (3), $C_{0}$ and $C_{e}$ are the initial and equilibrium metal ion concentrations $[\mathrm{mg} / \mathrm{l}]$ respectively.

\subsection{Adsorption Isotherm Studies}

The adsorption equilibrium data obtained were analyzed using the Langmuir and Freundlich adsorption isotherm model. The Langmuir isotherm can be expressed as given in $[14,15]$.

$$
q=\frac{a b C_{e}}{1+b C_{e}}
$$

This equation may be written in a linear form as provided in:

$$
\frac{C_{e}}{q}=\frac{1}{a b}+\frac{C_{e}}{q}
$$

Here, $\mathrm{q}$; is the amount of metal adsorbed per unit mass of adsorbent (mg/g); (a) and (b) are the Langmuir constants indicative of the maximum monolayer coverage capacity $(\mathrm{mg} / \mathrm{g})$ and energy of adsorption $(\mathrm{l} / \mathrm{mg})$ respectively; $\mathrm{C}_{\mathrm{e}}$ is the equilibrium metal ion concentration (mg/l). The Langmuir constants (a) and (b) were obtained from the intercept and slope of the linear plot of $\mathrm{C}_{\mathrm{e}} / \mathrm{q}$ against $\mathrm{C}_{\mathrm{e}}$.

The essential characteristics of the Langmuir isotherm is described by a separation factor or equilibrium constant $\mathrm{R}_{\mathrm{L}}$, which is defined by [16]:

$$
R_{L}=\frac{1}{1+b C_{o}}
$$

In (6), $C_{0}$ is the initial concentration of heavy metal ions $(\mathrm{mg} / \mathrm{l})$ and $b$ is the Langmuir constant related to the energy of adsorption. The separation factor $\mathrm{R}_{\mathrm{L}}$ indicates the isotherm shape and the favourability of the adsorption process depending on where it lies between 0 and 1 . The Freundlich isotherm is given by $[14,15]$ :

$$
\mathrm{q}=\mathrm{K}_{\mathrm{F}} \mathrm{C}_{\mathrm{e}}^{1 / \mathrm{n}}
$$

The linear form of the Freundlich isotherm is given by:

$$
\ln \mathrm{q}=\ln \mathrm{K}_{\mathrm{F}}+\frac{1}{\mathrm{n}} \ln \mathrm{C}_{\mathrm{e}}
$$

In (8), q: is the amount of metal adsorbed per unit mass of adsorbent $(\mathrm{mg} / \mathrm{g}) ; \mathrm{K}_{\mathrm{F}}$ is the Freundlich isotherm constant $(\mathrm{mg} / \mathrm{g}) ; \mathrm{C}_{e}$ is the equilibrium concentration $(\mathrm{mg} / \mathrm{l}) ; \mathrm{n}$ is the adsorption intensity. The values of $\mathrm{K}$ and $\mathrm{n}$ were calculated from the intercept and slope of the linear plot of $\ln q$ against $\ln$ Ce.

\subsection{Adsorption Kinetic Studies}

The pseudo first and pseudo second order kinetic models were used to analyze the kinetics of Fe (III) adsorption onto BSG. The pseudo first order rate equation is based on the assumption of reversibility of adsorbate-adsorbent interaction [17]. The integrated form of the model is expressed by:

$$
\frac{d q_{t}}{d t}=K_{1}\left(q_{e}-q_{t}\right)
$$

The linear form of this equation after integration is given by:

$$
\log \left(q_{e}-q_{t}\right)=\log q_{e}-\frac{K_{1} t}{2.303}
$$


Here, $\mathrm{q}_{\mathrm{e}}$ and $\mathrm{q}_{\mathrm{t}}$ are the amount of metal ions adsorbed at equilibrium and time $(\mathrm{t})$ respectively $(\mathrm{mg} / \mathrm{g}) ; \mathrm{t}$ is the time ( $\mathrm{min}$ ); $\mathrm{K}_{1}$ is the pseudo first order adsorption rate constant. The adsorption parameters are determined from the linear plot of $\log \left(\mathrm{q}_{\mathrm{e}}-\mathrm{q}_{\mathrm{t}}\right)$ against t. The Pseudo second order kinetic rate model is expressed using:

$$
\frac{d q_{t}}{d t}=K_{2}\left(q_{e}-q_{t}\right)^{2}
$$

The linear form of the model is written as:

$$
\frac{t}{q_{t}}=\frac{1}{K_{2} q_{e}^{2}}+\left(\frac{1}{q_{e}}\right) \cdot t
$$

Here, $\mathrm{q}_{\mathrm{e}}$ and $\mathrm{q}_{\mathrm{t}}$ are the amount of metal ions adsorbed at equilibrium and time $(\mathrm{t})$ respectively $(\mathrm{mg} / \mathrm{g})$; $\mathrm{t}$ is the time $(\mathrm{min}) ; \mathrm{K}_{2}$ is the pseudo second order adsorption rate constant. The adsorption parameters are determined from the linear plot of $t / \mathrm{q}_{\mathrm{t}}$ against $\mathrm{t}$ [18].

\section{RESULTS AND DISCUSSIONS}

\subsection{Characterization of Brewers' Spent Grain (BSG)}

From the results of characterization studies as presented in Table 1, it was observed that the $\mathrm{pH}$ of BSG was 7.7, which indicates an alkaline condition. The moisture content was $2.1 \%$ revealing that the material was used in its dry state. When the methylene blue value and iodine number of BSG were used as input parameters for the structural characterization software, a surface area of $234 \mathrm{~m}^{2} / \mathrm{g}$ was obtained. In addition, the micropore and total pore volume were given as $0.05 \pm 0.00 \mathrm{~cm}^{3} / \mathrm{g}$ and $0.15 \pm 0.02 \mathrm{~m}^{3} / \mathrm{g}$. The micropore volume and total pore volume are in line with the work of ElOuahabi et al. [25] in which the pore volume and total pore volume of some selected clay materials were recorded as 0.05 $\mathrm{cm}^{3} / \mathrm{g}$ and $0.015 \mathrm{~cm}^{3} / \mathrm{g}$ respectively. Surface area of $234 \mathrm{~m}^{2} / \mathrm{g}$ as compared with the works of ElOuahabi et al. [25] shows that BSG is a good candidate for Fe (III) ion removal.

From the results of Table 2, it was observed that the mass of Iron (III) oxide $\left(\mathrm{Fe}_{2} \mathrm{O}_{3}\right)$ present in BSG is low $(1.243 \mathrm{~g} / \mathrm{kg})$. The implications of this, is that BSG possesses higher adsorptive properties since a previous study has shown that the presence of iron impurities in adsorbent materials such as clay have effects on their ability to adsorb divalent metal ions [23]. The surface morphology of BSG was examined via SEM which revealed its macroporous structure as shown in Figure 1.

The highly macroporous structure as observed in Figure 1, indicates a higher surface area. This claim is based on the fact that as biosorbent materials present larger numbers of microporous structure, it adsorb higher amount of nitrogen, which resulted to a higher BET surface area [22].

Table 4: Physicochemical Properties of BSG

\begin{tabular}{ll}
\hline Parameter & Value \\
\hline Surface $\mathrm{pH}$ & 7.7 \\
Moisture Content (\%) & 2.1 \\
Ash Content $(\%)$ & 3.6 \\
Apparent Density (g/ml) & 0.68 \\
Methylene Blue Number (g/100g) & 7.7 \\
Iodine Value $(\mathrm{mg} / \mathrm{g})$ & 24.3 \\
Surface Area $\left(\mathrm{m}^{2} / \mathrm{g}\right)$ & $234 \pm 25$ \\
Micropore Volume $\left(\mathrm{cm}^{3} / \mathrm{g}\right)$ & $0.05 \pm 0.00$ \\
Total Pore Volume $\left(\mathrm{m}^{3} / \mathrm{g}\right)$ & $0.15 \pm 0.02$ \\
\hline
\end{tabular}

Table 5: Chemical Composition of BSG

\begin{tabular}{ll}
\hline Constituent & Value $(\mathrm{mg} / \mathrm{kg})$ \\
\hline $\mathrm{Fe}_{2} \mathrm{O}_{3}$ & 1243 \\
$\mathrm{MnO}_{2}$ & 70.26 \\
$\mathrm{ZnO}$ & 134.3 \\
$\mathrm{Na}_{2} \mathrm{O}$ & 558.3 \\
$\mathrm{~K}_{2} \mathrm{O}$ & 1192.1 \\
$\mathrm{MgO}$ & 202 \\
$\mathrm{CaO}$ & 832.2 \\
\hline
\end{tabular}

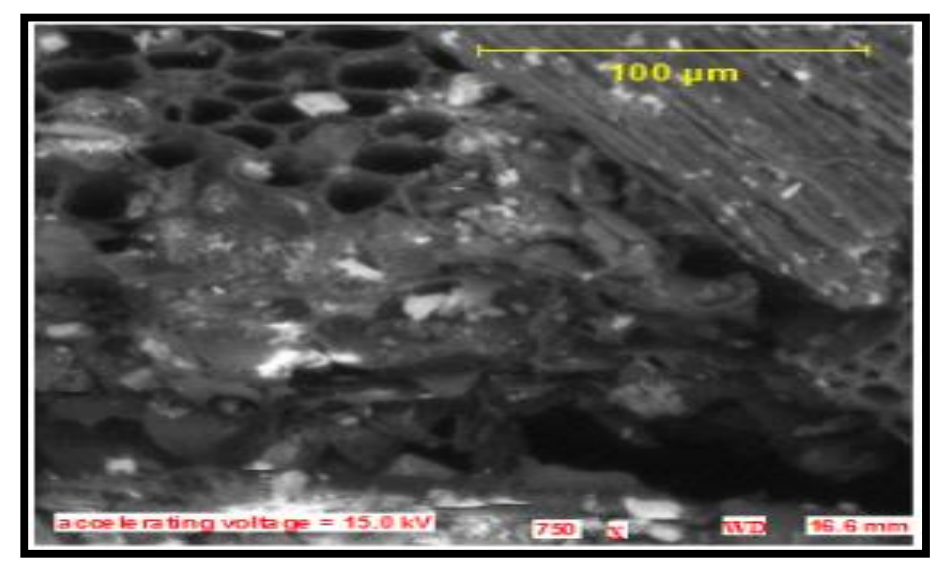

Figure 1: SEM of treated brewers' spent grain (x1000)

\subsection{Batch Adsorption Studies \\ 3.2.1 Optimum $p H$ Determination}

The effect of $\mathrm{pH}$ on the metal removal efficiency is illustrated in Figure 2. It can be observed that at $\mathrm{pH} 8$, maximum metal removal efficiencies of 69 and 84\% were achieved for raw and treated BSG respectively for an initial metal ion concentration of $5 \mathrm{mg} / \mathrm{l}$, adsorption contact time of 120 minutes and agitation speed of $100 \mathrm{rpm}$. At lower $\mathrm{pH}$ values, the percentage of metal ions taken up was less, as the adsorbent was more closely associated with hydroxonium $\left(\mathrm{H}_{3} \mathrm{O}^{-}\right)$ions by repulsive forces to the surface functional groups. These prevent the metal ions from approaching the 
binding sites on the adsorbent, thus resulting in decreased metal adsorption [10]. However at $\mathrm{pH}$ above 8.0 there was a decrease in the removal efficiency. This may be due to the formation of hydroxyl complexes resulting in precipitation, thus decreasing metal uptake [19].

\subsubsection{Effects of Adsorbent Dosage}

Figure 3 shows the effect of adsorbent dosage on sorption efficiency. Metal adsorption increased with increase in adsorbent dose. The sorption efficiency increased from 10 to $67 \%$ for raw BSG and 14 to $77 \%$ for treated BSG as the dosage increased from 0.2 to $1.0 \mathrm{~g}$ for an initial metal ion concentration of $5 \mathrm{mg} / \mathrm{l}$, adsorption contact time of 120 minutes and agitation speed of 100rpm. This can be attributed to the increased available surface area and functional groups for metal ions interaction and uptake. The increase in

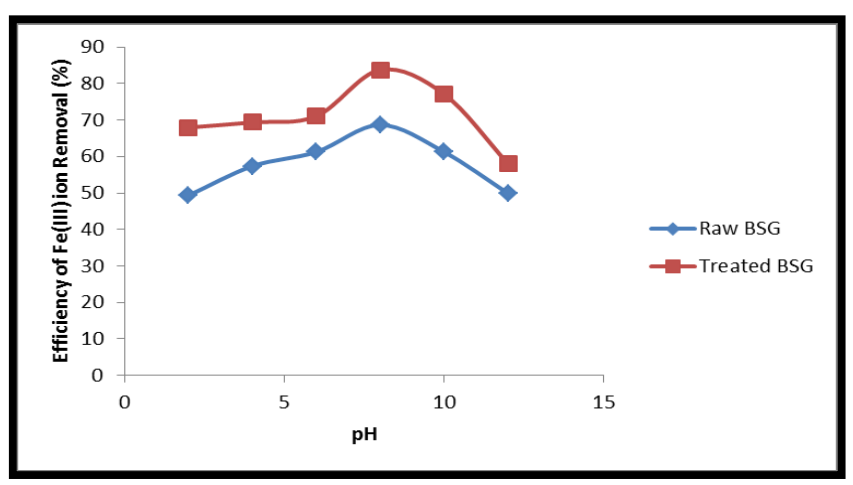

Figure 2: Effect of $p H$ on the efficiency of Fe(III) ion removal onto raw and treated $B S G$

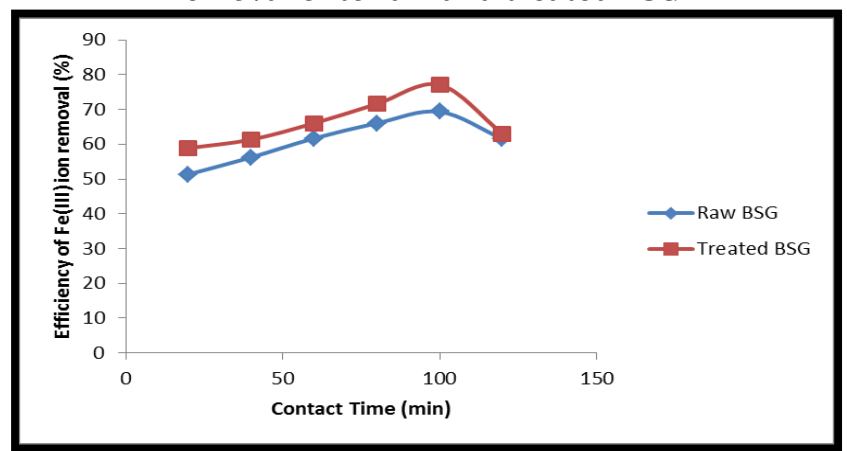

Figure 4: Effect of contact time on the efficiency of Fe(III) ion removal onto raw and treated BSG.

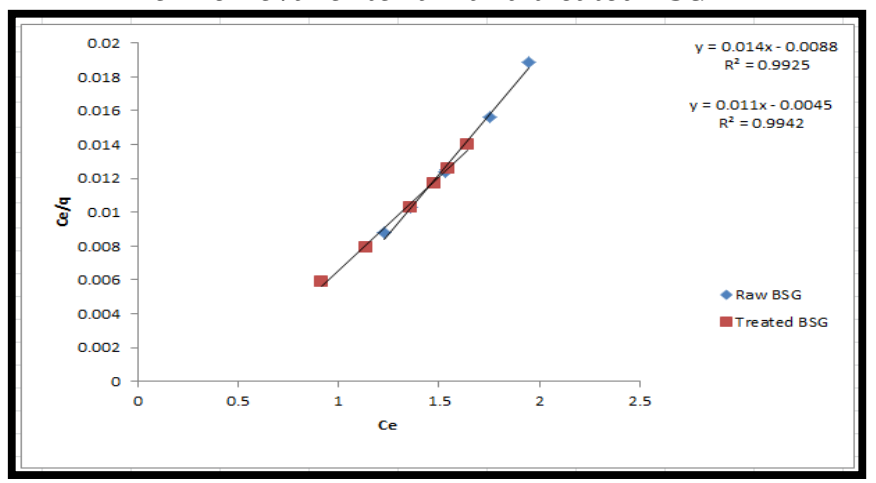

Figure 6: Langmuir isotherm for Fe(III) adsorption onto raw and treated $B S G$ metal ion adsorption with increasing dose of adsorbent as observed in Figure 3 may be due to the increase in availability of surface active sites resulting from the increased dose of the adsorbents [20]. This result is in-line with the works of Garg et al. [26].

\subsubsection{Effect of Contact Time}

Figure 4 shows the effect of contact time on the adsorption of Fe (III) ion onto BSG with an initial metal ion concentration of $5 \mathrm{mg} / \mathrm{l}$, adsorbent dose of $1.0 \mathrm{~g}$ and agitation speed of 100rpm. Contact time is an important factor which influences metal uptake. There was an increased rate of uptake observed at the early stage of adsorption process, which can be attributed to the availability of abundant active sites within the adsorbent surface, which gradually become occupied by the adsorbate with time.

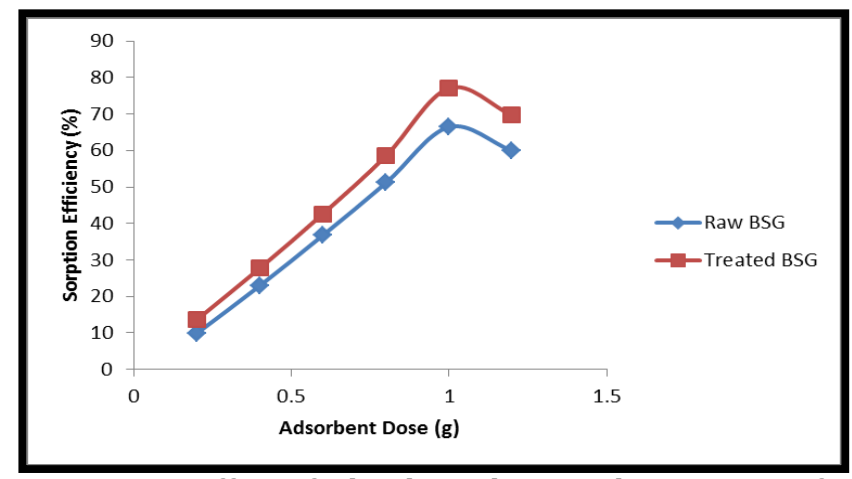

Figure 3: Effect of adsorbent dose on the sorption of $\mathrm{Fe}$ (III) onto raw and treated BSG

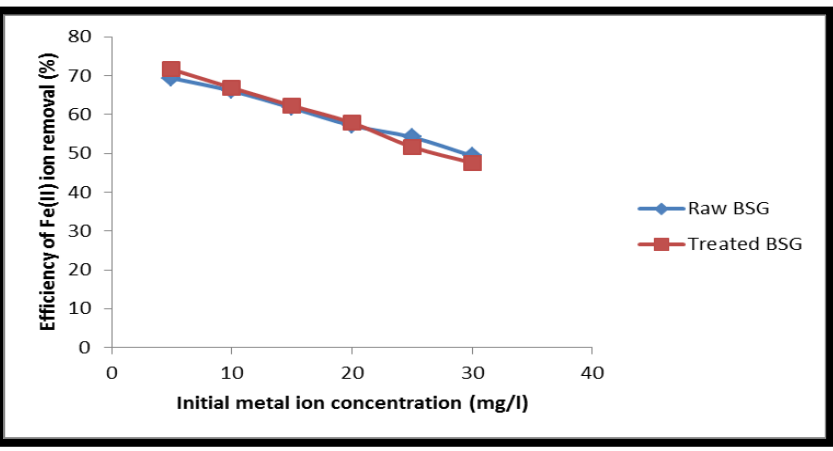

Figure 5: Effect of initial metal ion concentration on the efficiency of $\mathrm{Fe}$ (III) ion removal onto raw and treated BSG.

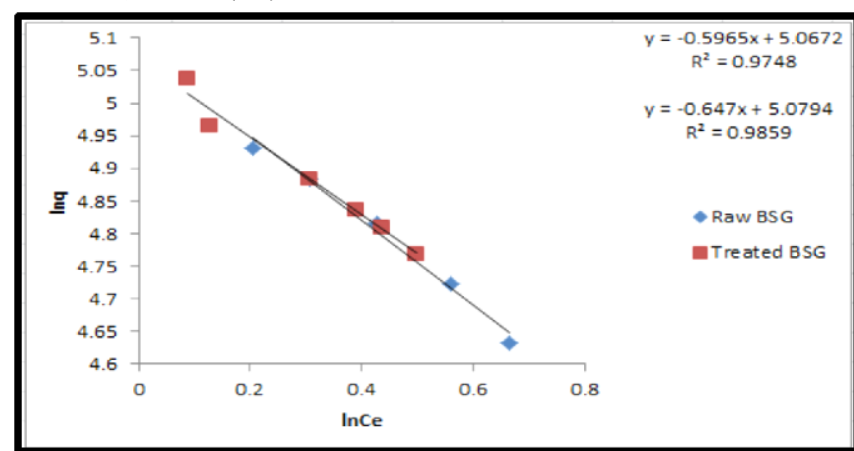

Figure 7: Freundlich isotherm for Fe(III) adsorption onto raw and treated $B S G$

Vol. 35, No. 4, October 2016 


\subsubsection{Effect of Initial Metal Concentration}

The effect of initial metal ion concentration on the percent removal efficiency of $\mathrm{Fe}$ (III) ion uptake onto raw and treated BSG is shown in Figure 5. The percent removal efficiency decreased steadily with increase in initial metal concentration. Fe (III) percent removal decreased from $69 \%$ at $5 \mathrm{mg} / \mathrm{l}$ to $49 \%$ at $30 \mathrm{mg} / \mathrm{l}$ for raw BSG and $72 \%$ at $5 \mathrm{mg} / \mathrm{l}$ to $48 \%$ at $30 \mathrm{mg} / \mathrm{l}$ for treated BSG. This is due to the availability of abundant higher energy sites at lower metal concentrations and the subsequent increased involvement of less energetic sorption sites as the metal concentration increased [12].

Table 6: Isotherm constants for the adsorption of Fe (III) ion onto raw and treated BSG

\begin{tabular}{lcccc}
\hline \multicolumn{5}{c}{ Langmuir Isotherm } \\
\hline Adsorbent & $\mathrm{a}(\mathrm{mg} / \mathrm{g})$ & $\mathrm{b}(\mathrm{l} / \mathrm{mg})$ & $\mathrm{R}_{\mathrm{L}}$ & $\mathrm{r}^{2}$ \\
\hline Raw BSG & 8.33 & 0.24 & 0.51 & 0.9940 \\
Treated BSG & 7 & 0.22 & 0.53 & 0.9946 \\
\hline \multicolumn{5}{c}{ Freundlich Isotherm } \\
\hline Raw BSG & $\mathrm{k}_{\mathrm{f}}(\mathrm{mg} / \mathrm{g})(\mathrm{mg} / \mathrm{l})^{-1 / \mathrm{n}}$ & $\mathrm{n}$ & $\mathrm{r}^{2}$ \\
\cline { 2 - 5 } Treated BSG & 0.75 & 0.71 & 0.9887 \\
\hline
\end{tabular}

\subsection{Adsorption Isotherm Studies}

The experimental data obtained were analyzed using the Langmuir and Freundlich isotherm models. The Langmuir and Freundlich isotherm plots are shown in Figures 6 and 7 respectively. The isotherm constants are presented in Table 3. It was observed that Langmuir isotherm model provided a better fit for the experimental data based on the higher values of the linear coefficient of determination $\left(\mathrm{r}^{2}\right)$ compared with the Freundlich isotherm model. The $\mathrm{r}^{2}$ values obtained from the Langmuir isotherm model are 0.9925 and 0.9942 for raw and treated BSG while the Freundlich isotherm model gave $\mathrm{r}^{2}$ values of 0.9859 and 0.986

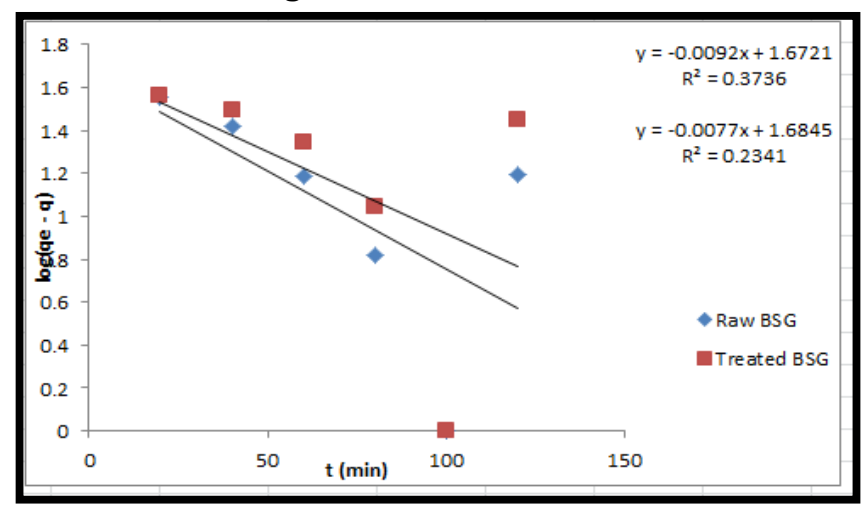

Figure 3.8: Pseudo first order kinetic model plot for $\mathrm{Fe}$ (III) ion adsorption onto BSG respectively. The Langmuir isotherm indicates homogenous monolayer adsorption on a finite number of active sites on the adsorbent [15]. The values of $\mathrm{R}_{\mathrm{L}}$ obtained were found to lie between 0 and 1 for the raw and treated BSG indicating that adsorption of Fe (III) onto BSG was favorable.

Since $\mathrm{R}_{\mathrm{L}}$ value is higher than zero but less than 1 as observed in Table 3, it was concluded that the adsorption of Fe (III) ion onto raw and treated BSG was favourable. The high values of $\left(\mathrm{r}^{2}\right)$ obtained also indicates the fitness of the adsorption data to the selected isotherm model.

\subsection{Kinetic Studies}

The adsorption kinetics is very important as it is a measure of the rate of reaction and describes the principal mechanisms involved in adsorption [17]. The experimental data were analyzed using the pseudo first and second order kinetic models as illustrated in Figures 8 and 9 respectively. The adsorption of $\mathrm{Fe}(\mathrm{III})$ onto raw and treated BSG was best described by the pseudo second order kinetic model based on the higher coefficient of determination ( $\mathrm{r}^{2}$ equals 0.9823 and 0.961 for raw and treated BSG respectively) as observed in Figure 9. The pseudo second order model is based on the assumption that chemisorption may be the rate limiting step and suggests that chemical reactions occur between the metal ions and the adsorbent resulting in the formation of strong covalent bonds $[17,18]$.

\section{CONCLUSION}

In this study, the use of brewer's spent grain (BSG) for the removal of Fe (III) ions from aqueous solution has been investigated, and it was observed from the overall result that BSG is a good adsorbent for metal ion removal.

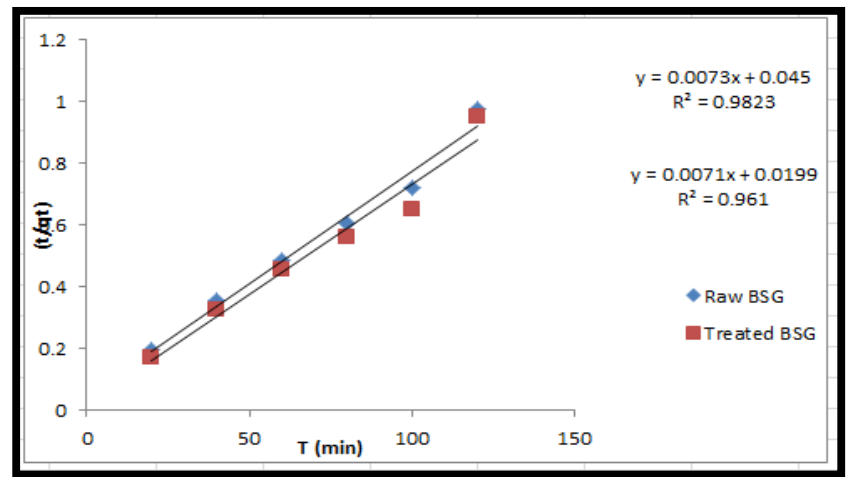

Figure 3.9: Pseudo second order kinetic model plot for $\mathrm{Fe}$ (III) ion adsorption onto BSG

Vol. 35, No. 4, October 2016 
It can thus be concluded that;

1. Microporous structures exist on the surface of BSG as revealed by the structural characterization and the scanning electron micrograph (SEM). The results attest to the adsorption potential of the raw and treated BSG as observed in the overall analysis.

2. Adsorbent produced from treated BSG showed very high potential in the removal of Fe (III) ions under optimized conditions of dosage $1.0 \mathrm{~g} / 50 \mathrm{ml}$, $5.0 \mathrm{mg} / \mathrm{l}$ initial concentration of iron under an equilibrium adsorption contact time of 120 minutes, $\mathrm{pH}$ of 8.0 and agitation speed of $100 \mathrm{rpm}$

3 . Based on the calculated values of the linear coefficient of determination $\left(r^{2}\right)$, the Langmuir isotherm model was found to be in better agreement with the experimental data compared with the Freundlich isotherm model.

4. The adsorption process followed a pseudo second order kinetics. This was evident from the result of Figures 8 and 9 respectively.

The findings of this study have demonstrated the potential of BSG as cost effective, environmental friendly alternative adsorbent for the treatment of $\mathrm{Fe}$ (III) ion contaminated solutions.

\section{REFERENCES}

[1] Srivastava, S. K., Singh A. K. and Sharma, A. "Studies on the uptake of lead and zinc by lignin obtained from black Liquor- A paper industry waste material", Environmental Technology. Vol. 15, , pp.353-361. (1994).

[2] Jain, M., Garg, V. K. and Kadirvelu, K. "Adsorption of hexavalent chromium from aqueous medium onto carbonaceous adsorbents prepared from waste biomass", Journal of Environmental Management. Vol. 91, , pp.949-957, (2010).

[3] Sousa, F. W., Oliveira, A. G., Ribeiro, J. P., Rosa, M. F., Keukeleire D. and Nascimento, R. F. "Green coconut shells applied as adsorbent for removal of toxic metal ions using fixed-bed column technology", Journal of Environmental Management. Vol. 91, , pp.1634-1640. (2010).

[4] Nadeem, M., Shabbir, M., Abdullah, M. A., Shah, S. S. and McKay, G. "Sorption of cadmium from aqueous solution by surfactant-modified carbon adsorbents", Chemical Engineering Journal. Vol. 148, , pp.365-370. (2009).

[5] Bailey, S .E., Olin, T. J., Bricka, R. M. and Adrian, D. D. "A review of potentially low cost sorbents for heavy metals", Water Research. Vol. 33, Number 11, , pp.2469-79. (1999).
[6] Al-Asheh, S., Banat, F. and Mohai, F. "Sorption of Copper and Nickel by spent animal bones", Chemosphere. Vol. 39, , pp.2087-2096. (1996).

[7] Li, Q., Chai, L., Yang, Z. and Wang, Q. "Kinetics and thermodynamics of $\mathrm{Pb}$ (II) adsorption onto modified spent grain from aqueous solutions", Applied Surface Science. Vol. 255, , pp.4298-4303. (2009).

[8] Adelagun, R. O. A., Itodo, A. U., Berezi, E. P., Okoh, O. J., Kamba, E. A., Andrew, C. and Bell, H. A. "Adsorptive Removal of $\mathrm{Cd}^{2+}$ and $\mathrm{Zn}^{2+}$ from Aqueous system by BSG", Chemistry and Materials Research. Vol. 16, Number 2, pp.104-112. (2014).

[9] Lu, S., and Gibb, S. W. "Copper removal from wastewater using spent-grain as bio sorbent", Bioresource Technology. Vol. 99, , pp.1509-1517. (2008).

[10] Low, K. S., Lee, C. K. and Liew, S. C. "Sorption of cadmium and lead from aqueous solutions by spent Grain", Process Biochemistry. Vol. 36, pp.59-64. (2000).

[11] Dawodu, F. A., Akpomie, G. K., Ejikeme, M. E. and Ejikeme, P. C. N. "The use of Ugwuoba clay as an adsorbent for zinc (II) ions from solution", International Journal of Multidisciplinary Science and Engineering. Vol. 3, Number 8, pp.13 - 18. (2012),

[12] Gunay, A., Arslankaya, E. and Tosun, I.o"Lead removal from aqueous solution by natural and pretreated clinoptilolite: adsorption equilibrium and kinetics", Journal of Hazardous Materials. Vol. 146, Numbers1-2, ,pp. 362-371. (2007).

[13] Eba, F., Gueu, S., Eya, A., Mvongbote, A., Ondo, J. A., Yao, B. K., Ndong, J. N. and Kouya, R. B. "Evaluation of the adsorption capacity of the natural clay from Bikougou (Gabon), to remove manganese (II) from aqueous solution", International Journal of Engineering Science and Technology. Vol. 2, Number 10, , pp. 5001-5016, (2010).

[14] Mohamed, M. and Ouki, S. "Removal mechanisms of toluene from aqueous solutions by chitin and chitosan", Industrial and Engineering Chemistry Research. Vol. 50,pp. 9557-9563

[15] Foo, K. Y. and Hameed, B. H. "Insights into the modeling of adsorption isotherm systems", Chemical Engineering Journal. Vol. 156, Number1, ,pp.2-10. (2010).

[16] Qadeer, R. "Adsorption of ruthenium ions on activated charcoal: influence of temperature on the kinetics of the adsorption process", Journal of Zhejiang University Science. Vol. 6B, Number 5, pp.353-356. (2004).

[17] Sen Gupta, S. and Bhattacharyya, K. G. "Kinetics of adsorption of metal ions on inorganic materials: A review", Advances in Colloid and Interface Science. Vol. 162, Number 1-2, pp.39-58. (2011),

[18] Ho, Y. S. and McKay, G. M. "Pseudo second order 
model for sorption process", Process Biochemistry, Vol. 34, , pp.451 - 465. (1999).

[19] Akgul, M., Karabakan, A., Acar, O. and Yurum, Y. "Removal of silver (I) from aqueous solutions with clinoptilolite", Microporous and Mesoporous Materials. Vol. 94, Number. 1-3, pp. 99-104. (2006).

[20] Saeed, A., Iqbal, M. and Akhtar, M. W. "Removal and recovery of lead (II) from single and multimetal $(\mathrm{Cd}, \mathrm{Cu}, \mathrm{Ni}, \mathrm{Zn})$ solutions by crop milling waste (black gram husk)", Journal of Hazardous Materials, Vol. 117, Number 1, pp.65-73. (2005),

[21] ASTM, D4607-94, Standard method for the determination of iodine number of activated carbon, pp; 1-9

[22] Abdullah, A. H., Anuark, P., Zulkarnain, Z., Mohd, Z. H., Dzulkefly, K., Faujan, A. and Ong, S. W. "Preparation and characterization of activated carbon from gelam wood bark (Melaleuca Cajuputi)", Malaysian Journal of Analytical Science. Vol. 7, Number 1, , pp. 65-68. (2001).

[23] Baumgartner, E., Blesa, M. A., Marinovich, H. A. and Marota, A. J. G. "Heterogeneous electron transfer as pathway in the dissolution of magnetite in oxalic acid solution", Inorganic Chemistry Journal, Vol. 22, ,pp. 2224-2226. (1983).

[24] Cleiton, A., Nunese, M. and Guerreiro C., "Estimation of surface area and pore volume of activated carbon by methylene blue and iodine numbers", Quim Nova, Vol. 34, Number 3, , pp. 472 - 476. (2011).

[25] ElOuahabi, M., Daoud, L., Vleeschouwer, F. D., Bindler, R. and Fagel, N. "Potentiality of clay raw materials from Northern Morocco in ceramic industry; Tetouan and Mekness areas", Ecology and Environmental Science Journal, Vol. 13, , pp. 1-23. (2009).

[26] Garg, V. K., Gupta, R., Yadav, A. and Kumar, K. “Dye removal from aqueous solution by adsorption on treated sawdust", Bioresource Technology Journal, Vol. 89, , pp. 121-124. (2003).

[27] James, O. O., Adediran, M.M., Adekola, F. A., Odebunmi, E. O. and Adekeye, J. I. D. "Beneficiation and characterization of bentonite from NorthEastern Nigeria", Journal of the North Carolina Academy of Science, Vol. 124, Number 4, , pp.154158. (2008).

[28] Rengaraj, S., Seung-Hyeon, M. and Sivabalm, S. "Agricultural solid waste for the removal of organics: adsorption of phenol from water and wastewater by palm seed coat activated carbon", Waste Management Vol. 22, pp. 543-548. (2002).

[29] Salwa, D. A. and El-Hinnawi, E. "Characterization of Egyptian smectitic clay deposit by methylene blue adsorption", America Journal of Applied Sciences, Vol. 8, Number 12, , pp. 1282-1286. (2011). 